\title{
Fried food consumption, genetic risk, and body mass index: gene-diet interaction analysis in three US cohort studies
}

\begin{abstract}
Qibin Qi assistant professor ${ }^{12}$, Audrey Y Chu research fellow ${ }^{3}$, Jae H Kang assistant professor ${ }^{4}$, Jinyan Huang research fellow ${ }^{5}$, Lynda M Rose statistician ${ }^{3}$, Majken K Jensen assistant professor ${ }^{1}$, Liming Liang assistant professor ${ }^{5}$, Gary C Curhan professor ${ }^{45}$, Louis R Pasquale associate professor $^{46}$, Janey L Wiggs associate professor $^{6}$, Immaculata De Vivo associate professor ${ }^{4}$, Andrew T Chan associate professor ${ }^{47}$, Hyon $\mathrm{K}$ Choi professor ${ }^{48}$, Rulla M Tamimi associate professor $^{45}$, Paul M Ridker professor ${ }^{3910}$, David J Hunter professor ${ }^{145}$, Walter C Willett professor ${ }^{145}$, Eric B Rimm associate professor ${ }^{145}$, Daniel I Chasman associate professor ${ }^{310}$, Frank B Hu professor $^{145}$, Lu Qi assistant professor ${ }^{14}$
\end{abstract}

'Department of Nutrition, Harvard School of Public Health, Boston, MA, USA; ${ }^{2}$ Department of Epidemiology and Population Health, Albert Einstein College of Medicine, Bronx, NY, USA; ${ }^{3}$ Division of Preventive Medicine, Department of Medicine, Brigham and Women's Hospital and Harvard Medical School, Boston, MA, USA; ${ }^{4}$ Channing Division of Network Medicine, Department of Medicine, Brigham and Women's Hospital and Harvard Medical School, Boston, MA, USA; ${ }^{5}$ Department of Epidemiology, Harvard School of Public Health, Boston, MA, USA; ${ }^{6}$ Department of Ophthalmology, Mass Eye and Ear Infirmary, Harvard Medical School, Boston, MA, USA; ${ }^{7}$ Division of Gastroenterology, Massachusetts General Hospital and Harvard Medical School, Boston, MA, USA; ${ }^{8}$ Section of Rheumatology and Clinical Epidemiology Unit, Boston University School of Medicine, Boston, MA, USA; ${ }^{9}$ Division of Cardiovascular Disease, Department of Medicine, Brigham and Women's Hospital and Harvard Medical School, Boston, MA, USA; ${ }^{10}$ Division of Genetics, Department of Medicine, Brigham and Women's Hospital and Harvard Medical School, Boston, MA, USA

\begin{abstract}
Objective To examine the interactions between genetic predisposition and consumption of fried food in relation to body mass index (BMI) and obesity.

Design Prospective cohort study.

Setting Health professionals in the United States.

Participants 9623 women from the Nurses' Health Study, 6379 men from the Health Professionals Follow-up Study, and a replication cohort of 21421 women from the Women's Genome Health Study.

Main outcome measure Repeated measurement of BMI over follow-up.

Results There was an interaction between fried food consumption and a genetic risk score based on $32 \mathrm{BMI}$-associated variants on $\mathrm{BMI}$ in both the Nurses' Health Study and Health Professionals Follow-up Study ( $P \leq 0.001$ for interaction). Among participants in the highest third of the genetic risk score, the differences in BMI between individuals who consumed fried foods four or more times a week and those who
\end{abstract}

consumed fried foods less than once a week amounted to 1.0 (SE 0.2) in women and 0.7 (SE 0.2) in men, whereas the corresponding differences were 0.5 (SE 0.2) and 0.4 (SE 0.2) in the lowest third of the genetic risk score. The gene-diet interaction was replicated in the Women's Genome Health Study ( $\mathrm{P}<0.001$ for interaction). Viewed differently, the genetic association with adiposity was strengthened with higher consumption of fried foods. In the combined three cohorts, the differences in BMI per 10 risk alleles were 1.1 (SE 0.2), 1.6 (SE 0.3), and 2.2 (SE 0.6) for fried food consumption less than once, one to three times, and four or more times a week $(\mathrm{P}<0.001$ for interaction); and the odds ratios (95\% confidence intervals) for obesity per 10 risk alleles were 1.61 (1.40 to 1.87 ), 2.12 (1.73 to 2.59 ), and 2.72 (2.12 to 3.48 ) across the three categories of consumption ( $P=0.002$ for interaction). In addition, the variants in or near genes highly expressed or known to act in the central nervous system showed significant interactions with fried food consumption, with the FTO (fat mass and obesity associated) variant showing the strongest result $(\mathrm{P}<0.001$ for interaction). 
Conclusion Our findings suggest that consumption of fried food could interact with genetic background in relation to obesity, highlighting the particular importance of reducing fried food consumption in individuals genetically predisposed to obesity.

\section{Introduction}

Obesity is a complex multifaceted condition that has a genetic basis but requires environmental influence to manifest itself. ${ }^{1-4}$ Over the past three decades, there has been a global increase in the prevalence of obesity, ${ }^{5}$ which many believe has been primarily driven by changes in lifestyles. It seems, however, that the adipogenic response to environmental exposures varies by genetic background, supporting the possible existence of interactions between genes and diet/lifestyle factors. ${ }^{23}$ 6-13

The prevalence of obesity in the United States is much higher than in other countries, and the greater consumption of fast foods is one of the notable differences between the US and the rest of the world. ${ }^{14}$ Frying is a common and traditional cooking procedure in Western countries, especially outside of the home. Fried foods make up a substantial proportion of the items sold at fast food restaurants that are patronized by about a third of Americans every day. ${ }^{15-17}$ Several previous studies have reported that fried food consumption alone or a Western-style diet pattern heavily loaded with fried foods is positively associated with obesity and related chronic diseases. ${ }^{18-25}$ Such studies, however, did not consider the potential modification by an individual's genetic make-up. It is unknown whether obesity related genetic factors can modify the association between fried food consumption and adiposity.

We examined the interaction between frequency of fried food consumption (both at home and away from home) and a genetic risk score based on 32 well established genetic variants associated with BMI in relation to BMI and obesity in women and men from two prospective cohorts: the Nurses' Health Study and Health Professionals Follow-up Study. The findings were replicated in a large independent prospective cohort, the Women's Genome Health Study.

\section{Methods}

\section{Study population}

The Nurses' Health Study is a prospective cohort study of 121 700 female registered nurses aged 30-55 at study inception in $1976 .{ }^{26}$ The Health Professionals Follow-up Study is a prospective cohort study of 51529 US male health professionals aged 40-75 at study inception in $1986 .{ }^{27}$ In both cohorts, information about medical history, lifestyle, and health conditions has been collected by self administered questionnaires every two years since inception. For this analysis, we used 1984 as baseline for the Nurses' Health Study and 1986 as baseline for Health Professionals Follow-Up Study, when the first data on fried food consumption were collected. The current analysis included 9623 initially healthy women and 6379 initially healthy men of European ancestry with genotype data available based on previous genome-wide association studies. ${ }^{28-33}$

The Women's Genome Health Study is a prospective cohort of US female healthcare professionals aged 45 and older and free from major chronic disease, including cancer and cardiovascular disease, at study entry (1992-94). ${ }^{34}$ Information related to health and lifestyle was collected by questionnaire at baseline and continuing observational follow-up. A total of 21421 women with confirmed self reported European ancestry had genotyping and dietary data available, were free from diabetes at baseline, and were included in the current analysis.

\section{Assessment of consumption of fried foods and other dietary factors}

We used similar semiquantitative food frequency questionnaires to assess intakes of food and beverage in the Nurses' Health Study ${ }^{35}$ Health Professionals Follow-Up Study ${ }^{36}$ and Women's Genome Health Study. ${ }^{35}$ In the food frequency questionnaires participants were asked how often they consumed fried foods at home and away from home. We did not ask about specific frying method, but most fried foods in the US are deep fried. Both questions had four to five response choices, ranging from never to daily. In the current analysis, we coded three categories of frequency of consumption consistently across questionnaires from all cohorts (less than once a week, once to three times a week, and four and more times a week). We analyzed consumption of fried food at home and away from home separately and combined to examine total consumption. Total consumption was correlated with saturated fat intake $(r=0.35$ in the Nurses' Health Study and 0.38 in the Health Professionals Follow-up Study) and trans-fat intake ( $r=0.42$ in the Nurses' Health Study and 0.42 in the Health Professionals Follow-up Study). We assessed diet quality with the alternative healthy eating index, which comprises nine components of dietary factors: vegetables, fruit, nuts and soy protein, ratio of white to red meat, cereal fiber, trans-fat, ratio of polyunsaturated to saturated fatty acids, duration of multivitamin use, and alcohol. ${ }^{37}$ A score for a Western diet pattern was also calculated based on 40 food groups by using factor analysis (principal component).$^{38}$ Participants with implausible energy intakes $(<800$ or $>4000$ $\mathrm{kcal} /$ day in men and $<500$ and $>3500 \mathrm{kcal} /$ day in women) were excluded from the analysis. The food frequency questionnaires were assessed in 1984 and 1986 and every four years thereafter in the Nurses' Health Study; in 1986 and every four years thereafter in the Health Professionals Follow-up Study; and once at baseline (1992-94) in the Women's Genome Health Study. The reproducibility and validity of the food frequency questionnaires have been evaluated with two repeated questionnaires and two to four diet records over a week at a one year interval. ${ }^{35} 3639$

\section{Assessment of BMI and covariates}

In the Nurses' Health Study and Health Professionals Follow-up Study, height and body weight were assessed by questionnaire at baseline, and weight was requested on each follow-up questionnaire. Self reported weights were highly correlated with measured weight ( $r=0.97$ in men and women) in a validation study. ${ }^{40} \mathrm{BMI}$ was calculated as body weight $(\mathrm{kg}) /$ height $(\mathrm{m})^{2}$. Participants with a BMI $\geq 30$ were defined as obese. Information about lifestyle factors was derived from the biennial questionnaires. ${ }^{26}{ }^{27}$ Physical activity was expressed as metabolic equivalents per week by using the reported time spent on various activities, weighting each activity by its intensity level. The validity of the self reported height, weight, and physical activity data has been described previously. ${ }^{40-42}$

In the Women's Genome Health Study, weight and physical activity were assessed by the baseline and follow-up questionnaires. Information about other lifestyle factors was collected from questionnaires at baseline. Details regarding the assessment of these variables have been reported previously. ${ }^{13} 43$

\section{Genotyping and computation of genetic risk score}

We selected 32 single nucleotide polymorphisms that represent all 32 loci associated with BMI at a genome-wide significance level $\left(\mathrm{P}<5 \times 10^{-8}\right)\left(\right.$ see appendix table A). ${ }^{44}$ Single nucleotide 
polymorphism genotyping and imputation have been described in detail elsewhere. ${ }^{13}{ }^{28-33}$ Most of the single nucleotide polymorphisms were genotyped or had a high imputation quality score (MACH $r^{2} \geq 0.8$ ). ${ }^{6}$

Genetic risk score was calculated on the basis of the 32 single nucleotide polymorphisms by using a previously reported weighted method. ${ }^{67}$ Each single nucleotide polymorphism was recoded as 0,1 , or 2 according to the number of risk alleles (BMI increasing alleles), and each single nucleotide polymorphism was weighted by its relative effect size $(\beta$ coefficient) derived from the previously reported meta-analysis data. ${ }^{44}$ We created the genetic risk score using the equation: genetic risk score $=\left(\beta_{1} \times \mathrm{SNP}_{1}+\beta_{2} \times \mathrm{SNP}_{2}+\ldots+\beta_{\mathrm{n}} \times \mathrm{SNP}_{\mathrm{n}}\right) \times$ (n/sum of the $\beta$ coefficients), where $\beta$ is the $\beta$ coefficient of each individual single nucleotide polymorphism on BMI, SNP is single nucleotide polymorphism, $\mathrm{n}$ is 32 , and sum of the $\beta$ coefficients is 4.39 in the current analysis. The genetic risk score ranges from 0 to 64 , and each point of the genetic risk score corresponded to each one risk allele.

\section{Statistical analyses}

We used $\chi^{2}$ tests and general linear models to compare proportions and means of baseline characteristics according to the frequency of total fried food consumption. We examined the association between consumption and BMI, according to the thirds of genetic risk score, using generalized linear models accounting for repeated measures within individuals. To minimize potential influence of reverse causality, we analyzed the data prospectively with the assessment of consumption four years prior to the assessment of BMI, including fried food consumption as independent variable and BMI four years later as the dependent variable in generalized linear models. Because of possible confounding from age related weight change in the elderly population, we used follow-up data only up to 1998 as the mean age of our study samples was over 65 after 1998. There were four repeated measures during 1984-98 in the Nurses' Health Study and three repeated measures during 1986-98 in the Health Professionals Follow-up Study. We also estimated the differences in BMI per increment of 10 risk alleles stratified by three categories of fried food consumption. An interaction between the genetic risk score and consumption on BMI was tested by including an interaction term in the models. Potential confounders considered in multivariable models were age (continuous), physical activity (in fifths), television watching (0-1, 2-5, 6-20, 21-40, >40 hours/week), smoking (never, past, current), alcohol intake (0, 0.1-4.9, 5.0-9.9, 10-14.9, $\geq 15 \mathrm{~g} /$ day), intake of sugar sweetened beverages $(<1$ serving/month, 1-4 servings/month, 2-6 servings/week, $\geq 1$ servings/day), alternative healthy eating index (in fifths), trans-fat intake (in fifths), Western-diet pattern score (in fifths), and total energy intake (in fifths). Similar analyses were repeated in the Women's Genome Health Study. As fried food consumption was assessed only once at baseline in the Women's Genome Health Study, we used general linear models (instead of generalized linear models with repeated measures analysis as applied in the Nurses' Health Study and Health Professionals Follow-up Study) to examine the interaction between the genetic risk score and fried food consumption on BMI three years later. In secondary analyses, we used logistic regression models to estimate odds ratios per increment of 10 risk alleles of obesity stratified by three categories of fried food consumption, using data on fried food consumption assessed at baseline and obesity status assessed four years later in the Nurses' Health Study and Health Professionals Follow-Up Study or three years later in the Women's Genome Health Study. Findings across cohorts were pooled with inverse variance weighted meta-analyses by fixed effects models (if $\mathrm{P} \geq 0.05$ for heterogeneity between studies) or random effects models (if $\mathrm{P}<0.05$ for heterogeneity between studies). All reported $\mathrm{P}$ values are nominal and two sided. Statistical analyses were performed in SAS 9.1 (SAS Institute, Cary, NC, USA) or R 2.13.0 (R Foundation, Vienna, Austria).

\section{Results}

\section{Baseline characteristics}

Baseline total consumption of fried food was positively associated with $\mathrm{BMI}$ at baseline in all three cohorts (all $\mathrm{P}<0.001)$ (table $1 \Downarrow$ ). Compared with participants with a lower frequency of consumption, those with a higher frequency were younger, tended to be smokers, and spent more time watching television. Participants who consumed more fried foods drank more sugar sweetened beverages and had higher total energy intakes and Western dietary pattern scores and lower levels of alcohol consumption, physical activity, and alternative healthy eating index. The genetic risk score ranged from 13 to 43 among our study participants. In all three cohorts, participants with a higher genetic risk score had a higher BMI (see appendix fig A). ${ }^{6}$ The genetic risk score was not associated with fried food intake, total energy intake, or other lifestyle factors (see appendix table B).

\section{Fried food consumption and BMI according to genetic risk score}

The association between total fried food consumption and BMI was stronger in participants with a higher genetic risk score than in those with a lower genetic risk score in both the Nurses' Health Study and Health Professionals Follow-up Study $(\mathrm{P}=0.005$ and 0.02 , respectively, for interaction) (table $2 \Downarrow$ ). Among participants in the highest third of the genetic risk score, the differences in BMI between individuals who consumed fried foods more than four times a week and those who consumed fried foods less than once a week amounted to 1.0 (SE 0.2) in the Nurses' Health Study and 0.7 (SE 0.2) in the Health Professionals Follow-Up Study, whereas the corresponding differences were 0.5 (SE 0.2) and 0.4 (SE 0.2) in the lowest third of the genetic risk score. We also found significant interactions for fried food consumed at home and consumed away from home in the Nurses' Health Study ( $\mathrm{P}=0.02$ and 0.01 , respectively, for interaction), and observed a similar but non-significant interaction pattern in the Health Professionals Follow-up Study ( $\mathrm{P}=0.07$ and 0.14 , respectively, for interaction). There was no significant heterogeneity in the interaction effects between these two cohorts (all $\mathrm{P}>0.17$ for heterogeneity). In addition, we performed a sensitivity analysis using the follow-up data up to 2008 from the Nurses' Health Study and Health Professionals Follow-up Study and found a similar but weaker interaction pattern (see appendix table C).

The significant interactions of the genetic risk score with total fried food consumption, fried food consumed at home, and fried food consumed away from home on BMI were replicated in the Women's Genome Health Study (all $\mathrm{P}<0.001$ for interaction) (table $2 \Downarrow$ ). The difference in BMI between individuals who consumed fried foods more than four times a week and those who consumed fried foods less than once a week was more pronounced among participants in the highest thirds (1.7, SE $0.2)$ than those in the lowest third of the genetic risk score $(0.8$, SE 0.2 ). In the three cohorts combined (fig $1 \Downarrow$ ), the association between fried food consumption and BMI strengthened across the thirds of the genetic risk score; viewed differently, the 
association between the genetic risk score and BMI was more pronounced in those who often ate fried foods.

\section{Genetic association with BMI and risk of obesity according to fried food consumption}

The genetic association with BMI consistently strengthened across the three categories of total fried food consumption in the Nurses' Health Study, Health Professionals Follow-up Study and the Women's Genome Health Study $(\mathrm{P}<0.001,0.01$, and $<0.001$, respectively, for interaction) (fig 2, top panel $\Downarrow$ ). For total fried food consumption less than once, one to three times, and four or more times a week, respectively, the increases in BMI per increment of 10 risk alleles were 1.3 (SE 0.1), 1.8 (SE 0.2 ), and 2.3 (SE 0.3) in the Nurses' Health Study; 0.7 (0.1 SE), 0.9 (SE 0.2 SE), and 1.2 (0.2 SE) in the Health Professionals Follow-Up Study; 1.4 (SE 0.1), 2.0 (SE 0.2), and 3.1 (SE 0.3) in Women's Genome Health Study, and 1.1 (SE 0.2), 1.6 (SE 0.3 ), and 2.2 (SE 0.6) in the pooled cohorts. The results did not change materially after further adjustment for Western dietary pattern score, trans-fat intake, interaction terms between the genetic risk score and dietary and lifestyle factors (physical activity, intake of sugar sweetened beverages, and television watching (Nurses' Health Study and Health Professionals Follow-up Study only)) in the Nurses' Health Study, Health Professionals Follow-up Study, and Women's Genome Health Study ( $\mathrm{P}<0.001,0.02$, and $<0.001$, respectively, for interaction). We also found similar interaction patterns for fried food consumed at home and away from home (see appendix fig B). No significant heterogeneity in the interaction effects was observed among the three cohorts (all $\mathrm{P}>0.15$ for heterogeneity). In addition, there was a significant interaction between the genetic risk score and total fried food consumption on obesity in the combined three cohorts ( $\mathrm{P}=0.002$ for interaction), and the odds ratios ( $95 \%$ confidence intervals) for obesity per 10 risk alleles were 1.61 (1.40 to 1.87 ), 2.12 (1.73 to 2.59), and 2.72 (2.12 to 3.48) for total fried food consumption of less than once, once to three times, and four or more times a week, respectively (table $3 \Downarrow$ ). For fried food consumed at home and away from home, we also observed significant interactions with obesity in the combined three cohorts $(\mathrm{P}=0.003$ and 0.02 respectively for interaction). No significant heterogeneity in the interaction effects was observed in the three cohorts (all $\mathrm{P}>0.43$ for heterogeneity).

We also examined the interactions between total fried food consumption and 32 single nucleotide polymorphisms in relation to BMI individually (see appendix table D). In the combined three cohorts, four single nucleotide polymorphisms in or near FTO, GNPDA2, NEGR1, and SEC16B loci showed nominally significant interactions with total fried food consumption on BMI (all $\mathrm{P}<0.05$ for interaction). Among them, only the FTO genetic variant $(\mathrm{P}<0.001$ for interaction in the pooled data) remained significant at $\mathrm{P}<0.002(0.05 / 32)$ after correction for multiple testing. The genetic association between the FTO variant and BMI consistently strengthened across the three categories of total fried food consumption in all the three cohorts (fig 2, bottom panel). $\Downarrow$ To further test whether the observed interaction between total fried food and the genetic risk score on BMI is driven by one specific genetic variant, we performed sensitivity analyses by excluding the significant genetic variant (FTO, GNPDA2, NEGR1, or SEC16B) each time in the calculation of the genetic risk score; the results were similar (all $\mathrm{P}<0.05$ for interaction in all three cohorts and $\mathrm{P}<0.001$ for interaction in the pooled data).

\section{Discussion}

We found a significant interaction between fried food consumption and genetic predisposition to adiposity in two prospective cohorts of US women and men. The findings were further replicated in a large independent cohort of US women. These results for the first time suggest that individuals with a greater genetic predisposition to adiposity might be more susceptible to the adverse influence of overconsumption of fried food on adiposity; and overconsumption of fried foods might magnify genetic effects on adiposity.

\section{Results in relation to other studies}

In previous studies, high consumption of fried food has been associated with increased adiposity and risk of obesity. ${ }^{20212325}$ In a cross sectional study of 33542 Spanish people, fried food intake was positively associated with general and central obesity. ${ }^{23}$ Recently, Mozaffarian and colleagues reported that increased fried food consumption (both at home and away from home) was significantly associated with weight gain among 120 877 US women and men. ${ }^{20}$ In addition, greater consumption of fried food away from home was associated with a higher BMI and weight gain in US children and adolescents. ${ }^{17}$ In the present study, we found that the magnitude of association between fried food consumption and BMI varied among individuals with different genetic predispositions to adiposity. This is in line with findings from previous twin studies that genetic risk could modulate relations between environmental factors and adiposity. ${ }^{45-47}$ Consistently, we found that individuals with a greater genetic predisposition to adiposity seemed to be more susceptible to the obesogenic effects of sugar sweetened beverages. ${ }^{6}$

Viewed from the other perspective, our study also suggests that fried food consumption could modify the genetic association with adiposity. The combined genetic effect on BMI among individuals who consumed fried foods more than four times a week was about twice as large as that among those who consumed fried foods less than once a week. It is not surprising that the observed interaction was more evident on BMI than on risk of obesity as these genetic variants were identified through genome-wide association studies of attained BMI, ${ }^{44}$ and the statistical power was lower for analysis on the dichotomous outcome (obesity) than a continuous variable (BMI). Several studies have shown that physical activity could attenuate the effect of a single genetic variant in the FTO gene as well as the combined genetic effect of multiple variants on BMI and obesity risk. $^{7-9}$ In contrast, an obesogenic diet and sedentary lifestyle with relatively higher intake of sugar sweetened beverages and prolonged television watching might exaggerate the genetic influences on adiposity. ${ }^{67}$ Taken together, these data suggest that a healthy diet and lifestyle could attenuate, at least partly, the risk of obesity attributed to genetic susceptibility.

Consistent with our previous analyses,${ }^{67}$ we primarily applied the approach using a genetic risk score based on 32 well established BMI variants rather than a single locus to test for interaction. As expected, because of the limited power to detect the relatively small effects conferred by each locus, most of the individual variants showed consistent but non-significant interactions with fried food consumption in relation to BMI. Among these variants, the FTO genetic variant showed the strongest interaction with fried food consumption on BMI. This is in line with the recent finding that FTO genetic variant was associated with phenotypic variability of BMI, suggesting interactions between FTO and environment in relation to BMI. ${ }^{48}$ Previous studies have consistently found that FTO genetic 
variants could interact with the effect of total energy intake, ${ }^{13}$ total fat intake, ${ }^{11}$ and saturated fat intake ${ }^{12}$ on BMI or risk of obesity, or both. We also observed that several other loci, such as GNPDA2, NEGR1, SEC16B, and MC4R, showed potential interactions with fried food consumption on BMI. Interestingly, these genes are highly expressed or known to act in the central nervous system involved in the regulation of appetite or energy balance. ${ }^{49}{ }^{50}$ Nevertheless, future studies are needed to validate our results on individual genetic variants, which could provide more insights into their function at a biological level.

\section{Potential mechanisms}

Several diet and lifestyle factors are correlated with fried food consumption. In our study, individuals who consumed larger amounts of fried food tended to have unhealthier eating habits, higher total energy intake, lower levels of physical activity, and higher levels of sedentary behavior. Fried food consumption might be an indicator of an unhealthy diet and lifestyle. It is difficult to separate out whether fried food consumption per se or other correlated unhealthy lifestyle interacts with genetic predisposition to adiposity. The observed interaction between fried food consumption and the genetic risk score in relation to BMI and obesity, however, was independent of multiple diet and lifestyle factors. We further adjusted for the interaction terms between the genetic risk score and the factors that previously showed a significant interaction with genetic predisposition to adiposity (sugar sweetened beverages, physical activity, and television watching), ${ }^{67}$ and the results remained unchanged.

Foods become crunchy, aromatic, palatable, and rich in fat after frying, ${ }^{5152}$ and eating fried foods might therefore result in high intake of foods with high fat, high energy density, and low satiety index. In addition, fried food absorbs some degradation products of the frying oil, such as polymers and polar compounds, which have been reported to be associated with some chronic diseases. ${ }^{53-56}$ It is unclear how these factors could account for the observed interaction. The BMI associated loci were recently identified by genome-wide association studies, and the biological functions of these genetic loci in relation to adiposity are poorly understood. ${ }^{44}$ It is possible that genes involved in the regulation of appetite (such as FTO and MC4R) could be underlying the observed interaction, but we could not exclude the involvement of other plausible biological hypotheses. The observed interaction on adiposity might reflect the cumulative effects of multiple genetic variants rather than any single variant. Determination of the precise mechanism will require more studies, especially functional experiments.

\section{Strengths and limitations}

The strengths of our study include the use of large cohort studies with long term follow-up, multiple measures of fried food consumption and BMI, comprehensive measures of diet and lifestyle factors, and the use of a genetic risk score combining genetic information of 32 variants associated with BMI. More importantly, the consistent findings of the gene-diet interactions in the three cohorts indicate the robustness of our results.

There are several limitations of our study. First, a causal relation among fried food consumption, genetic variants, and adiposity cannot be inferred from an observational study. Confounding by other unmeasured or unknown factors might exist, although we have carefully adjusted for multiple diet and lifestyle factors. Second, the information about the specific foods our participants consumed at home or away from home, the type of oil used for frying, the type of frying procedure performed, the time and temperature used for frying, and the number of times the oils had been reused was not collected in our study cohorts. This could limit our in depth analyses on these factors for their interactions with the genetic predisposition. Third, measurement errors in fried food consumption and other dietary factors are inevitable, but the food frequency questionnaires have been well validated in our cohorts. ${ }^{35}$ Fourth, we were unable to test sex differences within each cohort because of the single sex study design. Our analyses indicate, however, that there was no significant heterogeneity in the observed interactions between the cohorts of women (Nurses' Health Study and Women's Genome Health Study) and men (Health Professionals Follow-Up Study). In addition, the BMI associated loci identified to date account for only a small amount of variation (about $1.5 \%$ ) in BMI, ${ }^{44}$ and, consistently, the genetic risk score explained $1.5-1.8 \%$ of variation in BMI in our study. Finally, the participants included in our study were middle aged and older adults of European ancestry recruited in the US, and it is unknown whether our findings could be generalized to other demographic or ethnic groups.

\section{Conclusion}

In summary, the consistent results from three cohorts indicate that the association between fried food consumption and adiposity might vary according to differences in genetic predisposition; and, vice versa, the genetic influences on adiposity might be modified by fried food consumption. Our findings further emphasize the importance of reducing consumption of fried food in the prevention of obesity, particularly in individuals genetically predisposed to adiposity.

Contributors: $Q Q$ and $L Q$ designed the study and wrote the first draft. QQ and AYC analyzed the data. JHK, MKJ, GCC, LRP, JLW, IDV, ATC, HKC, RMT, PMR, DJH, WCW, EBR, DIC, FBH, and LQ were involved in data collection. JH, LMR, and LL provided statistical expertise. All authors contributed to the interpretation of the results and critical revision of the manuscript for important intellectual content and approved the final version of the manuscript. $Q Q$ and $L Q$ are guarantors.

Funding: This study was supported by grants DK091718, HL071981, HL073168, CA87969, CA49449, CA055075, HL34594, HL088521, U01HG004399, DK080140, P30DK46200, U01CA137088, U54CA155626, DK58845, DK098311, U01HG004728, EY015473, CA134958, DK70756 and DK46200 from the National Institutes of Health, with additional support for genotyping from Merck Research Laboratories, North Wales, PA. The Women's Genome Health Study is supported by HL043851, HL080467 and CA047988 from the National Institutes of Health, with collaborative scientific support and funding for genotyping provided by Amgen. LQ is a recipient of the American Heart Association Scientist Development Award (0730094N). LRP is supported by the Arthur Ashley Williams Foundation and a Harvard Ophthalmology Scholar Award (Harvard Medical School) from the Harvard Glaucoma Center of Excellence. ATC is a Damon Runyon Cancer Foundation Clinical Investigator. The funding sources had no role in the design or conduct of the study; collection, management, analysis, and interpretation of the data; or preparation, review, or approval of the manuscript.

Competing interests: All authors have completed the ICMJE uniform disclosure form at www.icmje.org/coi_disclosure.pdf (available on request from the corresponding author) and declare: no support from any organization for the submitted work; no financial relationships with any organizations that might have an interest in the submitted work in the previous three years, no other relationships or activities that could appear to have influenced the submitted work.

Ethical approval: The study protocol was approved by the institutional review boards of the Brigham and Women's Hospital, and the Harvard 


\section{What is already known on this topic}

Consumption of fried food and a genetic risk score based on 32 variants are associated with adiposity

Interaction between fried food consumption and genetic predisposition in relation to adiposity has not been examined

\section{What this study adds}

The association between consumption of fried foods and adiposity is strengthened by genetic predisposition

The genetic influences on adiposity are amplified by regular consumption of fried foods

School of Public Health. The completion of the self administered questionnaire was considered to imply informed consent.

Data sharing: No additional data available.

Transparency: The lead authors (the manuscript's guarantors) affirm that this manuscript is an honest, accurate, and transparent account of the study being reported; that no important aspects of the study have been omitted; and that any discrepancies from the study as planned (and, if relevant, registered) have been explained.

1 Xia Q, Grant SF. The genetics of human obesity. Ann N Y Acad Sci 2013;1281:178-90. 2 Phillips CM. Nutrigenetics and metabolic disease: current status and implications for personalised nutrition. Nutrients 2013:5:32-57.

3 Vliet-Ostaptchouk JV, Snieder H, Lagou V. Gene-lifestyle interactions in obesity. Curr Nutr Rep 2012;1:184-96.

4 El-Sayed Moustafa JS, Froguel P. From obesity genetics to the future of personalized obesity therapy. Nat Rev Endocrinol 2013;9:402-13.

5 Obesity: preventing and managing the global epidemic. Report of a WHO Consultation. World Health Organ Tech Rep Ser 200;894:1-253.

6 Li S, Zhao JH, Luan J, Ekelund U, Luben RN, Khaw KT, et al. Physical activity attenuates the genetic predisposition to obesity in 20,000 men and women from EPIC-Norfolk Prospective Population Study. PLOS Med 2010;7:e1000332.

7 Qi Q, Chu AY, Kang JH, Jensen MK, Curhan GC, Pasquale LR, et al. Sugar-sweetened beverages and genetic risk of obesity. N Engl J Med 2012;367:1387-96.

8 Qi Q, Li Y, Chomistek AK, Kang JH, Curhan GC, Pasquale LR, et al. Television watching leisure time physical activity, and the genetic predisposition in relation to body mass index in women and men. Circulation 2012;126:1821-27.

9 Kilpeläinen TO, Qi L, Brage S, Sharp SJ, Sonestedt E, Demerath E, et al. Physical activity attenuates the influence of FTO variants on obesity risk: a meta-analysis of 218,166 adults and 19,268 children. PLoS Med 2011;8:e1001116.

10 Corella D, Ortega-Azorín C, Sorlí JV, Covas MI, Carrasco P, Salas-Salvadó J, et al. Statistical and biological gene-lifestyle interactions of MC4R and FTO with diet and physica activity on obesity: new effects on alcohol consumption. PLOS ONE 2012;7:e52344.

11 Sonestedt E, Roos C, Gullberg B, Ericson U, Wirfält E, Orho-Melander M. Fat and carbohydrate intake modify the association between genetic variation in the FTO genotype and obesity. Am J Clin Nutr 2009:90:1418-25

12 Corella D, Arnett DK, Tucker KL, Kabagambe EK, Tsai M, Parnell LD, et al. A high intake of saturated fatty acids strengthens the association between the fat mass and obesity-associated gene and BMI. J Nutr 2011;141:2219-25.

13 Ahmad T, Lee IM, Pare G, Chasman DI, Rose L, Ridker PM, et al. Lifestyle interaction with fat mass and obesity-associated (FTO) genotype and risk of obesity in apparently healthy U.S. women. Diabetes Care 2011;34:675-80.

14 Lin BH, Guthrie J, Frazao E. Nutrient contribution of food away from home. Agriculture Information Bulletin No. 750: America's eating habits: changes and consequences. US Department of Agriculture, Economic Research Service, 1999:213-39.

15 Bowman SA, Vinyard BT. Fast food consumption of U.S. adults: impact on energy and nutrient intakes and overweight status. J Am Coll Nutr 2004;23:163-8.

16 Guthrie JF, Lin B-H, Frazao E. Role of food prepared away from home in the american diet, 1977-78 versus 1994-96: changes and consequences. J Nutr Educ Behav 2002;34:140-50.

17 Bowman SA, Gortmaker SL, Ebbeling CB, Pereira MA, Ludwig DS. Effects of fast-food consumption on energy intake and diet quality among children in a national household survey. Pediatrics 2004;113:112-8.

18 Donfrancesco C, Lo Noce C, Brignoli O, Riccardi G, Ciccarelli P, Dima F, et al. Italian network for obesity and cardiovascular disease surveillance: a pilot project. BMC Fam Pract 2008:9:53.

19 Lutsey PL, Steffen LM, Stevens J. Dietary intake and the development of the metabolic syndrome. Circulation 2008;117:754-61

20 Mozaffarian D, Hao T, Rimm EB, Willett WC, Hu FB. Changes in diet and lifestyle and long-term weight gain in women and men. N Engl J Med 2011;364:2392-404.

21 Taveras EM, Berkey CS, Rifas-Shiman SL, Ludwig DS, Rockett HRH, Field AE, et al. Association of consumption of fried food away from home with body mass index and die quality in older children and adolescents. Pediatrics 2005;116:e518-24.

22 Wosje KS, Khoury PR, Claytor RP, Copeland KA, Hornung RW, Daniels SR, et al. Dietary patterns associated with fat and bone mass in young children. Am J Clin Nutr 2010;92:294-303.

23 Guallar-Castillón P, Rodríguez-Artalejo F, Fornés NS, Banegas JR, Etxezarreta PA, Ardanaz E, et al. Intake of fried foods is associated with obesity in the cohort of Spanish adults from the European Prospective Investigation into Cancer and Nutrition. Am J Clin Nutr 2007;86:198-205

24 Odegaard AO, Koh WP, Yuan J-M, Gross MD, Pereira MA. Western-style fast food intake and cardiometabolic risk in an eastern country. Circulation 2012;126:182-8.

25 Sayon-Orea C, Bes-Rastrollo M, Basterra-Gortari FJ, Beunza JJ, Guallar-Castillon P, de la Fuente-Arrillaga $\mathrm{C}$, et al. Consumption of fried foods and weight gain in a Mediterranean cohort: the SUN project. Nutr Metab Cardiovasc Dis 2013:23:144-50.

26 Colditz GA, Manson JE, Hankinson SE. The Nurses' Health Study: 20-year contribution to the understanding of health among women. $J$ Womens Health 1997;6:49-62.
27 Rimm EB, Giovannucci EL, Willett WC, Colditz GA, Ascherio A, Rosner B, et al. Prospective study of alcohol consumption and risk of coronary disease in men. Lancet 1991;338:464-8.

28 Cornelis MC, Monda KL, Yu K, Paynter N, Azzato EM, Bennett SN, et al. Genome-wide meta-analysis identifies regions on 7p21 (AHR) and 15q24 (CYP1A2) as determinants of habitual caffeine consumption. PLoS Genet 2011; 7:e1002033.

29 Jensen MK, Pers TH, Dworzynski P, Girman CJ, Brunak Sr, Rimm EB. Protein interaction-based genome-wide analysis of incident coronary heart disease. Circ Cardiovasc Genet 2011;4:549-56.

30 Wiggs JL, Hee Kang J, Yaspan BL, Mirel DB, Laurie C, Crenshaw A, et al. Common variants near CAV1 and CAV2 are associated with primary open-angle glaucoma in Caucasians from the USA. Hum Mol Genet 2011;20:4707-13.

31 Hunter DJ, Kraft P, Jacobs KB, Cox DG, Yeager M, Hankinson SE, et al. A genome-wide association study identifies alleles in FGFR2 associated with risk of sporadic postmenopausal breast cancer. Nat Genet 2007;39:870-74.

32 Qi L, Cornelis MC, Kraft P, Stanya KJ, Linda Kao WH, Pankow JS, et al. Genetic variants at 2q24 are associated with susceptibility to type 2 diabetes. Hum Mol Genet 2010;19:2706-15.

33 Kottgen A, Albrecht E, Teumer A, Vitart V, Krumsiek J, Hundertmark C, et al. Genome-wide association analyses identify 18 new loci associated with serum urate concentrations. Nat Genet 2013:45:145-54

34 Ridker PM, Chasman DI, Zee RYL, Parker A, Rose L, Cook NR, et al. Rationale, design, and methodology of the Women's Genome Health Study: a genome-wide association study of more than 25000 initially healthy American women. Clin Chem 2008;54:249-55.

35 Willett WC, Sampson L, Stampfer MJ, Rosner B, Bain C, Witschi J, et al. Reproducibility and validity of a semiquantitative food frequency questionnaire. Am J Epidemiol 1985;122:51-65.

36 Rimm EB, Giovannucci EL, Stampfer MJ, Colditz GA, Litin LB, Willett WC. Reproducibility and validity of an expanded self-administered semiquantitative food frequency questionnaire among male health professionals. Am J Epidemiol 1992;135:1114-26.

37 McCullough ML, Feskanich D, Stampfer MJ, Giovannucci EL, Rimm EB, Hu FB, et al. Diet quality and major chronic disease risk in men and women: moving toward improved dietary guidance. Am J Clin Nutr 2002;76:1261-71.

38 Hu FB, Rimm E, Smith-Warner SA, Feskanich D, Stampfer MJ, Ascherio A, et al. Reproducibility and validity of dietary patterns assessed with a food-frequency questionnaire. Am J Clin Nutr 1999;69:243-9.

39 Feskanich D, Rimm EB, Giovannucci EL, Colditz GA, Stampfer MJ, Litin LB, et al. Reproducibility and validity of food intake measurements from a semiquantitative food frequency questionnaire. J Am Diet Assoc 1993;93:790-6.

40 Rimm EB, Stampfer MJ, Colditz GA, Chute CG, Litin LB, Willett WC. Validity of self-reported waist and hip circumferences in men and women. Epidemiology 1990;1:466-73.

41 Pirie $\mathrm{P}$, Jacobs D, Jeffery R, Hannan P. Distortion in self-reported height and weight data. J Am Diet Assoc 1981;78:601-6.

42 Wolf AM, Hunter DJ, Colditz GA, Manson JE, Stampfer MJ, Corsano KA, et al. Reproducibility and validity of a self-administered physical activity questionnaire. Int $J$ Epidemiol 1994;23:991-9.

43 Weinstein AR, Sesso HD, Lee IM, Cook NR, Manson JE, Buring JE, et al. Relationship of physical activity vs body mass index with type 2 diabetes in women. JAMA 2004;292:1188-94.

44 Speliotes EK, Willer CJ, Berndt SI, Monda KL, Thorleifsson G, Jackson AU, et al. Association analyses of 249,796 individuals reveal 18 new loci associated with body mass index. Nat Genet 2010;42:937-48.

45 Silventoinen K, Hasselbalch AL, Lallukka T, Bogl L, Pietiläinen KH, Heitmann BL, et al. Modification effects of physical activity and protein intake on heritability of body size and composition. Am J Clin Nutr 2009;90:1096-103.

46 McCaffery JM, Papandonatos GD, Bond DS, Lyons MJ, Wing RR. Gene-environment interaction of vigorous exercise and body mass index among male Vietnam-era twins. Am J Clin Nutr 2009;89:1011-8.

47 Greenfield JR, Samaras K, Jenkins AB, Kelly PJ, Spector TD, Campbell LV. Moderate alcohol consumption, dietary fat composition, and abdominal obesity in women: evidence for gene-environment interaction. J Clin Endocrinol Metab 2003;88:5381-6.

48 Yang J, Loos RJF, Powell JE, Medland SE, Speliotes EK, Chasman DI, et al. FTO genotype is associated with phenotypic variability of body mass index. Nature 2012;490:267-72.

49 Thorleifsson G, Walters GB, Gudbjartsson DF, Steinthorsdottir V, Sulem P, Helgadottir $A$, et al. Genome-wide association yields new sequence variants at seven loci that associate with measures of obesity. Nat Genet 2009;41:18-24.

50 Willer CJ, Speliotes EK, Loos RJ, Li S, Lindgren CM, Heid IM, et al. Six new loci associated with body mass index highlight a neuronal influence on body weight regulation. Nat Genet 2009;41:25-34.

51 Pokorn J, Panek J, Trojakova L. Effect of food component changes during frying on the nutrition value of fried food. Forum Nutr 2003;56:348-50.

52 Fillion L, Henry CJK. Nutrient losses and gains during frying: a review. Int J Food Sci Nutr 1998:49:157-68.

53 Soriguer F, Rojo-Martínez G, Dobarganes MC, García Almeida JM, Esteva I, Beltrán M, et al. Hypertension is related to the degradation of dietary frying oils. Am J Clin Nutr 2003;78:1092-97.

54 Galeone C, Pelucchi C, Talamini R, Levi F, Bosetti C, Negri E, et al. Role of fried foods and oral/pharyngeal and oesophageal cancers. Br J Cancer 2005:92:2065-69. 
55 Dai Q, Shu XO, Jin F, Gao YT, Ruan ZX, Zheng W. Consumption of animal foods, cooking methods, and risk of breast cancer. Cancer Epidemiol Biomarkers Prev 2002;11:801-8. 56 Williams MJA, Sutherland WHF, McCormick MP, de Jong SA, Walker RJ, Wilkins GT. Impaired endothelial function following a meal rich in used cooking fat. $J$ Am Coll Cardiol 1999;33:1050-5.

Accepted: 31 January 2014
Cite this as: BMJ 2014;348:g1610

This is an Open Access article distributed in accordance with the Creative Commons Attribution Non Commercial (CC BY-NC 3.0) license, which permits others to distribute, remix, adapt, build upon this work non-commercially, and license their derivative works on different terms, provided the original work is properly cited and the use is non-commercial. See: http://creativecommons.org/licenses/by-nc/3.0/. 


\section{Tables}

Table 1| Baseline characteristics of participants according to frequency of total fried food consumption. ${ }^{*}$ Figures are means (SD) or percentages unless otherwise indicated.

Frequency/week

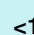

$<1$

1-3

$\geq 4$

$P$ value

Nurses' Health Study (women)

\begin{tabular}{|c|c|c|c|c|}
\hline No of participants & $4993(52 \%)$ & 3027 (31\%) & $1603(17 \%)$ & - \\
\hline Age (year) & $52.6(6.5)$ & $51.6(6.8)$ & $50.2(6.7)$ & $<0.001$ \\
\hline Body mass index $\left(\mathrm{kg} / \mathrm{m}^{2}\right)$ & $23.7(4.5)$ & $24.4(4.9)$ & $25.0(5.5)$ & $<0.001$ \\
\hline No $(\%)$ of current smokers (\%) & $949(19 \%)$ & $605(20 \%)$ & $356(22 \%)$ & $<0.001$ \\
\hline Physical activity (MET-h/week) & $15.7(20.7)$ & $12.8(15.9)$ & $10.7(13.5)$ & $<0.001$ \\
\hline Television watching (h/week) & $12.7(11.6)$ & $13.8(11.5)$ & $14.4(11.9)$ & $<0.001$ \\
\hline Total energy intake (kcal/day) & $1633(489)$ & $1821(509)$ & $2018(538)$ & $<0.001$ \\
\hline Alcohol consumption (g/day) & $7.4(11.3)$ & $7.1(11.7)$ & $6.2(10.1)$ & $<0.001$ \\
\hline $\begin{array}{l}\text { Sugar sweetened beverage intake } \\
\text { (servings/day) }\end{array}$ & $0.22(0.44)$ & $0.34(0.57)$ & $0.43(0.63)$ & $<0.001$ \\
\hline Alternative health eating index score & $40.7(10.6)$ & $37.3(10.0)$ & $36.0(9.6)$ & $<0.001$ \\
\hline Western dietary pattern score & $-0.35(0.86)$ & $0.18(0.92)$ & $0.71(1.06)$ & $<0.001$ \\
\hline Genetic risk score & $29.2(3.8)$ & $29.1(3.9)$ & $29.2(3.9)$ & 0.98 \\
\hline \multicolumn{5}{|c|}{ Health Professionals Follow-Up Study (men) } \\
\hline No of participants & $2402(38 \%)$ & $2072(32 \%)$ & $1905(30 \%)$ & - \\
\hline Age (year) & $55.7(8.6)$ & $54.6(8.6)$ & $52.8(8.6)$ & $<0.001$ \\
\hline Body mass index $\left(\mathrm{kg} / \mathrm{m}^{2}\right)$ & $25.4(3.1)$ & $25.8(3.2)$ & $26.2(3.4)$ & $<0.001$ \\
\hline No $(\%)$ of current smokers (\%) & $170(7 \%)$ & $170(8 \%)$ & $200(10 \%)$ & $<0.001$ \\
\hline Physical activity (MET-h/week) & $22.6(29.4)$ & $19.1(24.4)$ & $17.6(24.3)$ & $<0.001$ \\
\hline Television watching (h/week) & $10.9(8.6)$ & $11.7(8.5)$ & $12.2(8.7)$ & $<0.001$ \\
\hline Total energy intake (kcal/day) & $1866(566)$ & $2025(592)$ & $2224(632)$ & $<0.001$ \\
\hline Alcohol consumption (g/day) & $11.8(15.6)$ & $13.0(16.4)$ & $12.4(16.4)$ & 0.17 \\
\hline $\begin{array}{l}\text { Sugar sweetened beverage intake } \\
\text { (servings/day) }\end{array}$ & $0.21(0.42)$ & $0.31(0.49)$ & $0.45(0.62)$ & $<0.001$ \\
\hline Alternative health eating index score & $48.1(11.2)$ & $43.4(10.3)$ & $41.4(9.9)$ & $<0.001$ \\
\hline Western dietary pattern score & $-0.39(0.76)$ & $0.11(0.82)$ & $0.60(0.95)$ & $<0.001$ \\
\hline Genetic risk score & $29.2(3.8)$ & $29.0(3.9)$ & $29.0(3.8)$ & 0.20 \\
\hline \multicolumn{5}{|c|}{ Women's Genome Health Study (women) } \\
\hline No of participants & $14702(69 \%)$ & $4790(22 \%)$ & 1929 (9\%) & - \\
\hline Age (year) & $55.0(7.2)$ & $54.1(6.8)$ & $52.9(6.3)$ & $<0.001$ \\
\hline Body mass index $\left(\mathrm{kg} / \mathrm{m}^{2}\right)$ & $25.3(4.5)$ & $26.5(5.2)$ & $27.5(5.7)$ & $<0.001$ \\
\hline No $(\%)$ of current smokers (\%) & $1470(10 \%)$ & $504(11 \%)$ & $270(14 \%)$ & $<0.001$ \\
\hline Physical activity (MET-h/week) & $16.5(19.7)$ & $11.7(14.8)$ & $9.6(13.3)$ & $<0.001$ \\
\hline Total energy intake (kcal/day) & $1665(500)$ & $1842(529)$ & $2002(568)$ & $<0.001$ \\
\hline Alcohol consumption (g/day) & $4.6(8.5)$ & $4.1(8.7)$ & $3.3(7.5)$ & $<0.001$ \\
\hline $\begin{array}{l}\text { Sugar sweetened beverage intake } \\
\text { (servings/day) }\end{array}$ & $0.20(0.48)$ & $0.33(0.64)$ & $0.47(0.85)$ & $<0.001$ \\
\hline Alternative health eating index score & $42.4(9.6)$ & $37.4(9.1)$ & $34.3(8.6)$ & $<0.001$ \\
\hline Western dietary pattern score & $-0.20(0.72)$ & $0.32(0.76)$ & $0.70(0.82)$ & $<0.001$ \\
\hline Genetic risk score & $28.6(3.4)$ & $28.6(3.4)$ & $28.5(3.4)$ & 0.17 \\
\hline
\end{tabular}

*Baseline data from 9623 women in Nurses' Health Study (1984), 6379 men in Health Professionals Follow-Up Study (1986), and 21421 women in Women's Genome Health Study (1992). Physical activity assessed in 1986 for Nurses' Health Study. Television watching assessed in 1992 for Nurses' Health Study and in 1988 for Health Professionals Follow-Up Study. 


\begin{tabular}{|c|c|c|c|c|c|}
\hline \multirow[b]{2}{*}{ Genetic risk score } & \multicolumn{3}{|c|}{ Mean BMI by consumption/week } & \multirow[b]{2}{*}{$P$ for trend } & \multirow[b]{2}{*}{$P$ for interaction } \\
\hline & $<1$ & $1-3$ & $\geq 4$ & & \\
\hline \multicolumn{6}{|l|}{ Total consumption $\dagger$} \\
\hline \multicolumn{6}{|l|}{ Nurses' Health Study: } \\
\hline $1(<27.5)$ & $25.6(0.1)$ & $25.9(0.1)$ & $26.1(0.2)$ & 0.005 & \multirow[t]{3}{*}{0.005} \\
\hline $2(27.5-30.8)$ & $26.1(0.1)$ & $26.6(0.1)$ & $26.9(0.2)$ & $<0.001$ & \\
\hline $3(\geq 30.9)$ & $27.0(0.1)$ & $27.4(0.1)$ & $28.0(0.2)$ & $<0.001$ & \\
\hline \multicolumn{6}{|c|}{ Health Professionals Follow-Up Study: } \\
\hline $1(<27.5)$ & $25.7(0.1)$ & $25.9(0.1)$ & $26.1(0.1)$ & 0.01 & \multirow[t]{3}{*}{0.02} \\
\hline $2(27.5-30.8)$ & $26.0(0.1)$ & $26.2(0.2)$ & $26.6(0.1)$ & $<0.001$ & \\
\hline $3(\geq 30.9)$ & $26.4(0.1)$ & $26.7(0.1)$ & $27.1(0.1)$ & $<0.001$ & \\
\hline \multicolumn{6}{|c|}{ Fried food consumed at home $†$} \\
\hline \multicolumn{6}{|l|}{ Nurses' Health Study: } \\
\hline $1(<27.5)$ & $25.7(0.1)$ & $25.9(0.1)$ & $25.2(0.3)$ & 0.58 & \multirow[t]{3}{*}{0.02} \\
\hline $2(27.5-30.8)$ & $26.1(0.1)$ & $26.6(0.1)$ & $26.0(0.3)$ & 0.002 & \\
\hline $3(\geq 30.9)$ & $27.1(0.1)$ & $27.4(0.1)$ & $27.4(0.3)$ & 0.01 & \\
\hline \multicolumn{6}{|c|}{ Health Professionals Follow-Up Study: } \\
\hline $1(<27.5)$ & $25.8(0.1)$ & $25.9(0.1)$ & $25.8(0.3)$ & 0.53 & \multirow[t]{3}{*}{0.07} \\
\hline $2(27.5-30.8)$ & $26.1(0.1)$ & $26.4(0.1)$ & $26.3(0.3)$ & 0.04 & \\
\hline $3(\geq 30.9)$ & $26.5(0.1)$ & $27.0(0.1)$ & $26.6(0.3)$ & 0.04 & \\
\hline \multicolumn{6}{|c|}{ Fried food consumed away from home } \\
\hline \multicolumn{6}{|l|}{ Nurses' Health Study: } \\
\hline $1(<27.5)$ & $25.6(0.1)$ & $26.4(0.2)$ & $27.9(0.9)$ & $<0.001$ & \multirow[t]{3}{*}{0.01} \\
\hline $2(27.5-30.8)$ & $26.1(0.1)$ & $27.2(0.2)$ & $27.8(0.7)$ & $<0.001$ & \\
\hline $3(\geq 30.9)$ & $26.9(0.1)$ & $28.4(0.2)$ & $28.2(1.0)$ & $<0.001$ & \\
\hline \multicolumn{6}{|c|}{ Health Professionals Follow-Up Study: } \\
\hline $1(<27.5)$ & $25.7(0.1)$ & $26.1(0.1)$ & $26.3(0.3)$ & 0.002 & \multirow[t]{3}{*}{0.14} \\
\hline $2(27.5-30.8)$ & $26.0(0.1)$ & $26.4(0.1)$ & $27.4(0.3)$ & $<0.001$ & \\
\hline $3(\geq 30.9)$ & $26.5(0.1)$ & $26.9(0.1)$ & $27.1(0.4)$ & 0.002 & \\
\hline \multicolumn{6}{|c|}{ Replication phase in Women's Genome Health Studył } \\
\hline \multicolumn{6}{|c|}{ Total fried food consumption: } \\
\hline $1(<27.4)$ & $25.6(0.1)$ & $25.9(0.1)$ & $26.3(0.2)$ & $<0.001$ & \multirow[t]{3}{*}{$<0.001$} \\
\hline $2(27.4-30.6)$ & $26.1(0.1)$ & $26.9(0.1)$ & $27.3(0.2)$ & $<0.001$ & \\
\hline $3(\geq 30.7)$ & $26.7(0.1)$ & $27.5(0.1)$ & $28.6(0.2)$ & $<0.001$ & \\
\hline \multicolumn{6}{|c|}{ Fried food consumed at home: } \\
\hline $1(<27.4)$ & $25.7(0.1)$ & $25.9(0.1)$ & $25.8(0.5)$ & 0.03 & \multirow[t]{3}{*}{0.004} \\
\hline $2(27.4-30.6)$ & $26.3(0.1)$ & $26.7(0.1)$ & $26.7(0.4)$ & 0.05 & \\
\hline $3(\geq 30.7)$ & $26.9(0.1)$ & $27.5(0.1)$ & $28.9(0.5)$ & $<0.001$ & \\
\hline \multicolumn{6}{|c|}{ Fried food consumed away from home: } \\
\hline $1(<27.4)$ & $25.6(0.1)$ & $26.2(0.1)$ & $26.2(0.5)$ & $<0.001$ & $<0.001$ \\
\hline $2(27.4-30.6)$ & $26.1(0.1)$ & $27.2(0.1)$ & $28.7(0.6)$ & $<0.001$ & \\
\hline $3(\geq 30.7)$ & $26.8(0.1)$ & $28.2(0.1)$ & $30.0(0.6)$ & $<0.001$ & \\
\hline
\end{tabular}

*Data are least squares means (SE) of BMI (averages over follow-up) across categories of fried food consumption.

†Data derived from repeated measures analysis for women in Nurses' Health Study (four measures during 1984-98) and in Health Professionals Follow-Up Study (three measures during 1986-98), adjusted for age, source of genotyping data, physical activity, television watching, smoking, alcohol intake, sugar sweetened beverage intake, alternative healthy eating index, and total energy intake. Data on fried food consumption assessed four years before assessment of BMI. ‡Data derived from general linear regression analysis for women in Women's Genome Health Study, adjusted for age, physical activity, smoking, alcohol intake, sugar sweetened beverage intake, alternative healthy eating index, and total energy intake. Data on fried food consumption assessed three years before assessment of BMI. 


\begin{tabular}{|c|c|c|c|c|}
\hline & \multicolumn{3}{|c|}{ Consumption/week } & \multirow[b]{2}{*}{$P$ for interaction } \\
\hline & $<1$ & $1-3$ & $\geq$ & \\
\hline \multicolumn{5}{|l|}{ Total fried food consumption } \\
\hline \multicolumn{5}{|l|}{ Nurses' Health Study: } \\
\hline No of women (obese/normal weight) & $679 / 2888$ & $484 / 1666$ & $356 / 776$ & - \\
\hline Odds ratio $(95 \% \mathrm{Cl}) \dagger$ & 1.76 (1.39 to 2.24$)$ & 2.70 (2.00 to 3.65$)$ & 2.54 (1.75 to 3.69$)$ & 0.02 \\
\hline \multicolumn{5}{|l|}{ Health Professionals Follow-up Study: } \\
\hline No of men (obese/normal weight) & $194 / 1051$ & $216 / 830$ & $269 / 686$ & - \\
\hline Odds ratio $(95 \% \mathrm{Cl}) \dagger$ & 2.00 (1.27 to 3.13$)$ & 2.04 (1.31 to 3.20$)$ & 2.86 (1.88 to 4.36$)$ & 0.16 \\
\hline \multicolumn{5}{|l|}{ Women's Genome Health Study: } \\
\hline No of women (obese/normal weight) & $743 / 11673$ & $266 / 3423$ & $120 / 1234$ & - \\
\hline Odds ratio $(95 \% \mathrm{Cl}) \ddagger$ & 1.46 (1.19 to 1.78$)$ & 1.57 (1.11 to 2.21$)$ & 2.88 (1.68 to 4.94$)$ & 0.06 \\
\hline Pooled odds ratio $(95 \% \mathrm{Cl}) \S$ & $1.61(1.40$ to 1.87$)$ & 2.12 (1.73 to 2.59$)$ & $2.72(2.12$ to 3.48$)$ & 0.002 \\
\hline \multicolumn{5}{|l|}{ Fried food consumed at home } \\
\hline \multicolumn{5}{|l|}{ Nurses' Health Study: } \\
\hline No of women (obese/normal weight) & $808 / 3181$ & $567 / 1840$ & $138 / 299$ & - \\
\hline Odds ratio $(95 \% \mathrm{Cl}) \dagger$ & 1.73 (0.92 to 3.27$)$ & 2.46 (1.86 to 3.24$)$ & $4.52(2.33$ to 8.77$)$ & 0.006 \\
\hline \multicolumn{5}{|l|}{ Health Professionals Follow-up Study: } \\
\hline No of men (obese/normal weight) & $302 / 1396$ & $303 / 973$ & $71 / 188$ & - \\
\hline Odds ratio $(95 \% \mathrm{Cl}) \dagger$ & 2.12 (1.47 to 3.05$)$ & 2.57 (1.77 to 3.74$)$ & 1.96 (0.79 to 4.90$)$ & 0.69 \\
\hline \multicolumn{5}{|l|}{ Women's Genome Health Study: } \\
\hline No of women (obese/normal weight) & $939 / 13404$ & $208 / 2778$ & $17 / 211$ & - \\
\hline Odds ratio $(95 \% \mathrm{Cl}) \ddagger$ & $1.44(1.21$ to 1.73$)$ & $2.25(1.51$ to 3.35$)$ & $2.83(0.55$ to 14.52$)$ & 0.06 \\
\hline Pooled odds ratio $(95 \% \mathrm{Cl}) \S$ & 1.57 (1.34 to 1.83$)$ & 2.43 (2.00 to 2.96$)$ & $3.33(2.00$ to 5.55$)$ & 0.003 \\
\hline \multicolumn{5}{|l|}{ Fried food consumed away from home } \\
\hline \multicolumn{5}{|l|}{ Nurses' Health Study: } \\
\hline No of women (obese/normal weight) & $1110 / 4485$ & $375 / 805$ & $33 / 34$ & - \\
\hline Odds ratio $(95 \% \mathrm{Cl}) \dagger$ & 2.09 (1.73 to 2.52$)$ & 2.68 & .85)ף & 0.28 \\
\hline \multicolumn{5}{|l|}{ Health Professionals Follow-up Study: } \\
\hline No of men (obese/normal weight) & $351 / 1647$ & $257 / 810$ & $69 / 104$ & - \\
\hline Odds ratio $(95 \% \mathrm{Cl}) \dagger$ & 2.08 (1.49 to 2.91$)$ & 2.53 (1.69 to 3.79$)$ & $4.39(1.26$ to 15.25$)$ & 0.30 \\
\hline \multicolumn{5}{|l|}{ Women's Genome Health Study: } \\
\hline No of women (obese/normal weight) & $864 / 13750$ & $263 / 2611$ & $11 / 127$ & - \\
\hline Odds ratios $(95 \% \mathrm{Cl}) \ddagger$ & $1.52(1.27$ to 1.83$)$ & 1.84 (1.30 to 2.61$)$ & $5.19(0.45$ to 59.96$)$ & 0.17 \\
\hline Pooled odds ratio $(95 \% \mathrm{Cl}) \S$ & $1.81(1.60$ to 2.05$)$ & 2.29 (1.84 to 2.83$)$ & $4.53(1.49$ to 13.79$)$ & 0.02 \\
\hline
\end{tabular}

*Derived from logistic regression analyses, using data on fried food consumption assessed at baseline and obesity status assessed four years later in Nurses' Health Study and Health Professionals Follow-Up Study and three years later in Women's Genome Health Study.

†Data adjusted for age, source of genotyping data, physical activity, television watching, smoking, alcohol intake, sugar sweetened beverage intake, alternative healthy eating index, and total energy intake.

‡Data adjusted for age, physical activity, smoking, alcohol intake, sugar sweetened beverage intake, alternative healthy eating index, and total energy intake. $\S$ Results for three cohorts pooled by means of fixed effects meta-analyses (if $P \geq 0.05$ for heterogeneity between studies) or random effects meta-analyses (if $\mathrm{P}<0.05$ for heterogeneity between studies).

IFor fried food consumed away from home in Nurses' Health Study, participants in categories of 1-3/week and $\geq 4 /$ week combined because of small sample size in category of $\geq 4 /$ week. 


\section{Figures}
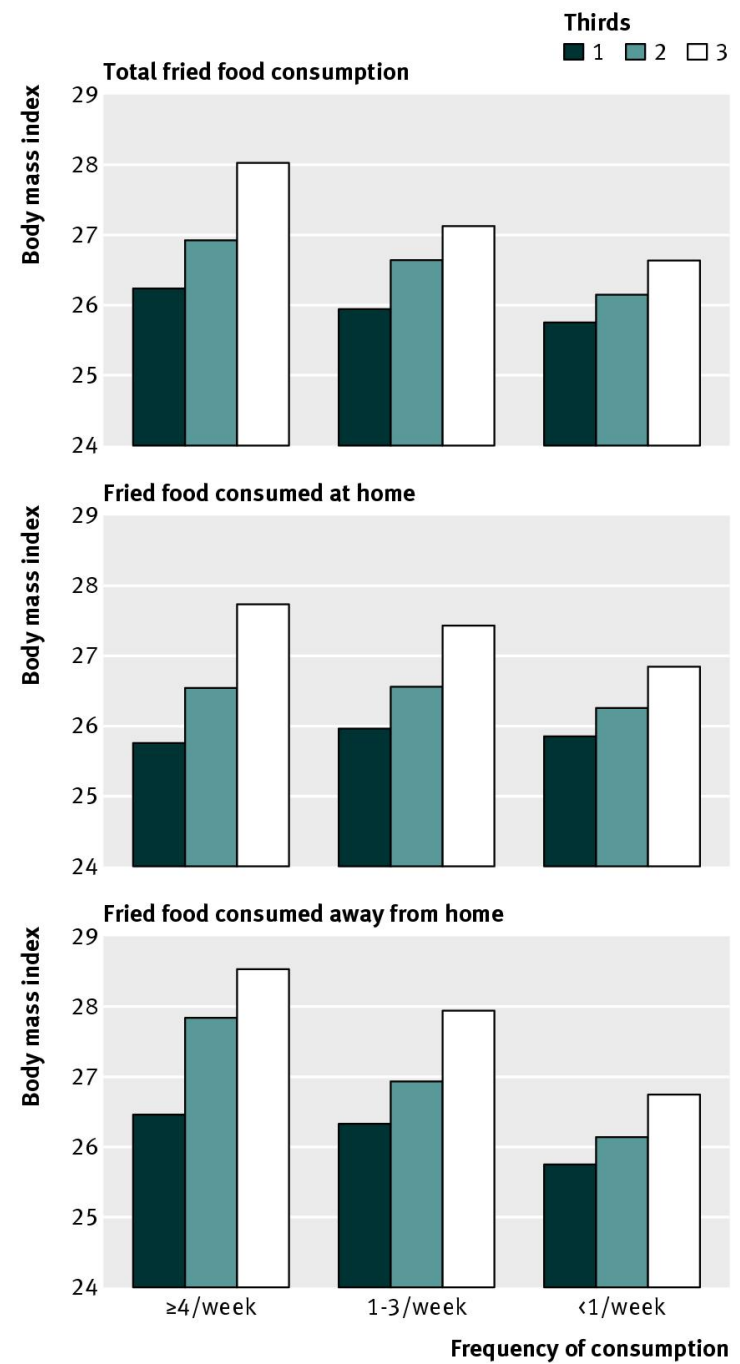

Fig $1 \mathrm{BMI}$ according to frequency of fried food consumption and thirds of genetic risk score in pooled data of three cohorts. Data adjusted for age, source of genotyping data, physical activity, television watching, smoking, alcohol intake, intake of sugar sweetened beverages, alternative healthy eating index, and total energy intake in Nurses' Health Study (NHS) and Health Professionals Follow-Up Study (HPFS); and age, physical activity, smoking, alcohol intake, intake of sugar sweetened beverages, alternative healthy eating index, and total energy intake In the Women's Genome Health Study (WGHS). Data from three cohorts were pooled by means of fixed effects meta-analyses (if $P \geq 0.05$ for heterogeneity between studies) or random effects meta-analyses (if $\mathrm{P}<0.05$ for heterogeneity between studies) 


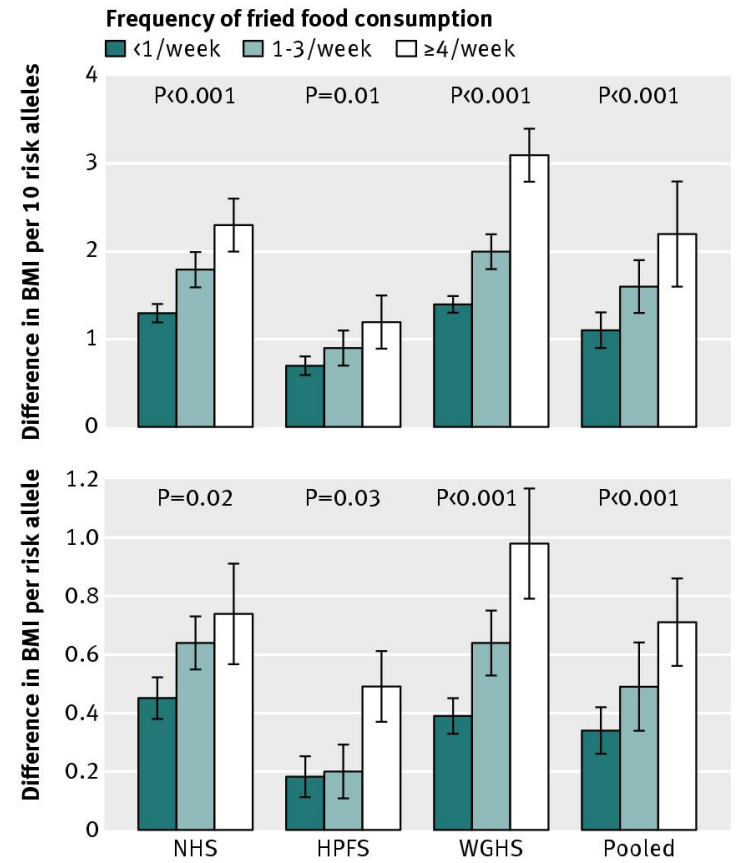

Fig 2 Genetic associations with BMI according to frequency of fried food consumption in three cohorts. Data are differences (SE) in BMI per 10 risk alleles of genetic risk score and differences (SE) in BMI per risk allele (A-allele) of the FTO (fat mass and obesity associated) variant rs1558902. In Nurses' Health Study (NHS) and Health Professionals Follow-Up Study (HPFS), data were adjusted for age, source of genotyping data, physical activity, television watching, smoking, alcohol intake, intake of sugar sweetened beverages, alternative healthy eating index, and total energy intake. In Women's Genome Health Study (WGHS), data were adjusted for age, physical activity, smoking, alcohol intake, intake of sugar sweetened beverages, alternative healthy eating index, and total energy intake. Data from three cohorts pooled by means of fixed effects meta-analyses (if $\mathrm{P} \geq 0.05$ for heterogeneity between studies) or random effects meta-analyses (if $\mathrm{P}<0.05$ for heterogeneity between studies) 